\title{
UTILIZAÇÃO DO MODELO DE REFERÊNCIA DE GESTÃO DA PRODUÇÃO MAKE-TO-ORDER - MTO (PRODUÇÃO SOB ENCOMENDA) POR UMA EMPRESA DO SETOR METALÚRGICO DE IGARAPAVA - SP ${ }^{1}$
}

\author{
OLIVEIRA, Diego Willian Domingos de ${ }^{2}$ \\ PENEDO, Antonio Sérgio Torres ${ }^{3}$
}

Recebido em: 2008-10-30

Aprovado em: 2009-01-19

ISSUE DOI: $10.3738 / 1982.2278 .153$

RESUMO: No mercado metalúrgico que se encontra em ascensão, as empresas do setor devem buscar constantemente a melhor forma de administrar seu meio produtivo, com isso destaca-se todo o processo de evolução que os sistemas produtivos passaram até os dias atuais. As empresas do setor metalúrgico utilizam o Modelo de Referência Make-to-Order (MTO) para conseguir atingir seus objetivos de produção com qualidade dentro dos prazos pré-estabelecidos, a fim de atender à demanda cada vez mais exigente do setor, estas empresas utilizam deste modelo para se adequarem às mudanças constantes no mercado, onde as necessidades dos clientes estão primeiramente em foco, para a obtenção de qualidade e eficiência em todo meio produtivo. Este modelo de referência distingue-se dos demais devido principalmente a este fator, o envolvimento direto com os clientes, outro modelo que se assemelha ao MTO é o Engineering to Order (ETO), que está ainda mais envolvido com as necessidades dos clientes, ou seja, estes modelos são focados conforme a real necessidade e características de cada cliente.

Palavras-chave: Produção sob encomenda. Metalúrgica. Referência de Gestão. Make-to-Order.

SUMMARY: In the metallurgical market that is rising, the companies of the sector must search constantly the best way to administrate their productive circle, so it can be pointed out the whole process of evolution of the productive systems passed until now. The companies of the metallurgical sector have used the reference model of Make-to-Order (MTO) to achieve their objectives of production with quality on pre-established time in order to serve the stricter demand of the sector. These companies have used this model to adjust to the constant changes on market, where the customers' needs are firstly focused to obtain the quality and the efficiency in all productive circles. This reference model is different from the others mainly due to this factor, the direct involvement with the customers. Another model that is similar to the MTO is the engineering-to-Order (ETO) that is more and more involved with the customers' needs, in other words, these models are focused according to each customer's real needs and characteristics.

Keywords: Production custom. Metallurgical. Reference Management. Make-to-Order.

\footnotetext{
1 Artigo apresentado como trabalho de Conclusão de Curso apresentado à Fundação Educacional de Ituverava. Faculdade de Filosofia Ciências e Letras para obtenção do título de Bacharel em Administração Habilitação em Gestão de Negócios.

1 Graduando do curso de Administração de Empresas Habilitação em Gestão de Negócios pela Faculdade de Filosofia Ciências e Letras de Ituverava - SP

1 Mestre em Administração de Empresa, doutorando em Engenharia da Produção, professor do curso de Administração de Empresas da Faculdade de Filosofia Ciências e Letras de Ituverava - SP.
} 


\section{INTRODUÇÃO}

O meio produtivo sofreu uma constante evolução com o passar dos anos, segundo Magnoli e Araujo (1993), a produção artesanal estende-se da idade média até o início da revolução industrial por volta dos séc. XVIII e XIX. A produção artesanal dependia da capacidade manual dos operários e das forças animais e naturais, este sistema produtivo quando utilizado no campo era de base familiar e dividia espaço com a agricultura, já o sistema de produção artesanal utilizado nos grandes centros produtivos era chamado de sistema de corporação de ofício.

Conforme Chiavenato (2007), no período compreendido entre os séculos XV e XIX ocorreu uma grande mudança no processo produtivo devido principalmente a primeira e segunda revolução industrial, a demanda por produtos industrializados aumentou substancialmente, a produção artesanal da lugar à manufatura em massa.

Todos esses fatores sobre o desenvolvimento dos processos produtivos foram importantíssimos para o crescimento do mercado global, os dois períodos de produção anteriormente citados serviram de base para a evolução dos processos até se chegar a um novo sistema que começou a se difundir por volta da década de 50, a chamada produção enxuta que também era conhecida como sistema Just-in-time (JIT). Essa evolução no modo de administrar os meios produtivos foi conseqüência da grande competitividade imposta pelo mercado, onde muitas organizações foram obrigadas a buscar um melhoramento contínuo em seu ambiente produtivo. (SLACK et. al. 2007)

No geral os três sistemas de produção têm seu valor histórico em todo processo de desenvolvimento no meio produtivo, desde a alta padronização no processo e alta qualificação dos operários no sistema artesanal, a alta padronização e baixa qualificação no sistema de produção em massa até chegar à maior flexibilidade e alta qualificação no processo de manufatura enxuta.

Com este estudo busca-se destacar essa evolução, e dar uma ênfase na utilização do sistema de manufatura enxuta com foco principal na Produção Sob Encomenda (Make-to-Order) em uma empresa do setor metalúrgico.

A escolha deste tema justifica-se em uma análise das necessidades de implementação do sistema de produção sob encomenda em uma empresa do setor metalúrgico, onde existe hoje uma grande competitividade no setor e também uma pressão para conseguir uma redução nos custos e um aumento contínuo na qualidade de seus produtos, outro fator de destaque é a grande complexidade em relação ao meio produtivo no setor, onde se torna um tema interessante para ser discutido. $\mathrm{O}$ tema foi 
delimitado para que possa ser feito uma avaliação comparativa na empresa analisada quanto a utilização, implementação e evolução do sistema em todo seu meio produtivo, podendo-se destacar as principais vantagens e desvantagens na adoção deste sistema.

O trabalho visa responder a seguinte pergunta: Qual a importância na utilização do modelo de referência Make-to-Order (produção sob encomenda) para uma empresa do setor metalúrgico no interior de São Paulo?

Este trabalho visa contextualizar essa evolução e analisar de forma clara e objetiva quais são os principais impactos decorrentes da adesão da produção sob encomenda (Make-to-Order) em uma empresa do setor metalúrgico do nordeste do estado de São Paulo, objetiva-se com o estudo analisar a importância da escolha da utilização de um processo produtivo com a implantação do sistema de produção sob encomenda em uma organização do setor metalúrgico. Assim, como objetivos secundários têm-se: identificar as principais aplicações do sistema em relação ao processo anteriormente utilizado e identificar os principais benefícios e problemas com a adoção deste sistema por uma empresa do setor automotivo.

Neste trabalho foi feita uma análise sistêmica da implantação do sistema MTO através de um roteiro de entrevista realizada com os profissionais responsáveis pela administração e implantação deste sistema, assim como os funcionários de nível gerencial ligados ao processo de utilização do sistema. $\mathrm{O}$ estudo utiliza de materiais fornecidos pela empresa analisada, e também materiais bibliográficos referentes ao estudo sobre o tema. Através desta metodologia procura-se elucidar todas as questões referentes ao trabalho, e desta forma expor uma análise sistêmica do mesmo buscando apresentar os principais benefícios e problemas com a adoção do sistema em questão.

\section{REVISÃO DE LITERATURA}

\subsection{CARACTERÍSTICAS DOS SISTEMAS PRODUTIVOS}

\section{- PRODUÇÃO ARTESANAL}

Conforme afirma Magnoli; Araújo (1993), a produção artesanal detinha várias particularidades no meio em que era inserido, quando utilizado no meio rural o sistema era de base familiar e no meio urbano era utilizado como corporação de ofício. A produção artesanal estendeu-se da idade média até o início dos séculos XVIII e XIX, e dependia da capacidade manual de seus operários e de forças animais e naturais. No 
campo dividia espaço com a agricultura, e nos grandes centros eram utilizadas em oficinas de produção, essas oficinas pertenciam a uma corporação que regulava o trabalho e restringia a concorrência entre as oficinas, cada mestre artesão dispunha de dois ou três aprendizes o que não permitia o desenvolvimento da divisão técnica do trabalho dentro de sua oficina. Conforme afirma Magnoli; Araújo (1993), eles detinham o conhecimento de todo processo produtivo. Já o mestre artesão detinha a propriedade, as ferramentas, as matérias-primas e os conhecimentos técnicos dentro de sua oficina, eram de responsabilidade dos mestres artesãos toda a administração e processos produtivos, desde a aquisição de matérias-primas até a finalização da venda de sua produção.

Martins (1993) afirma que o trabalho nas oficinas artesanais era caracterizado por uma alta qualidade de mão-de-obra, pois os aprendizes detinham o conhecimento de todo processo, a produção era de baixo volume e elevado custo devido à baixa padronização no processo produtivo, também é válido destacar que os produtos eram feitos sob encomenda e eram bastante customizados, pois os clientes eram pessoas de alto poder aquisitivo.

\section{- PRODUÇÃO EM MASSA}

Conforme Chiavenato (2000) no período que compreende os séculos XIX e XX, onde aconteceu às duas grandes revoluções industriais ocorreu um aumento substancial no processo produtivo, devido a esse aumento ocorre um crescimento na demanda por produtos industrializados e a produção artesanal dá lugar a uma nova realidade produtiva, Taylor e Fayol desenvolvem a administração científica e a teoria clássica respectivamente. Henry Ford, seguindo os preceitos de Taylor e Fayol, melhora substancialmente sua linha de produção industrial, nascendo com isso à chamada produção em massa.

No entendimento de Martins (1993), o principal objetivo da produção em massa era atingir grandes mercados consumidores, produzindo produtos industrializados de baixo custo, alta padronização e grandes volumes. Ford é o mais conhecido precursor da produção em massa, seu processo produtivo sintetiza bem este sistema e ele ajudou a popularizar o automóvel, que antes era um produto fabricado artesanalmente e destinado apenas a pessoas com alto poder aquisitivo, com a criação de seu Ford modelo "T", um carro altamente padronizado e destinado as grandes massas. 
Chiavenato (2000) afirma que por volta de 1926 a Ford Motor Company chegava a produzir mais de 2.000 .000 de veículos por ano em suas 88 fábricas espalhadas por todo país. A produção em massa diferencia-se da artesanal em vários aspectos, a produção é padronizada e em série, sua mão-de-obra é especializada em apenas uma tarefa, ou seja, os operários eram especializados somente na tarefa que lhe era transmitida, ele não tinha conhecimentos em outras tarefas, o sistema utilizado por Ford era conhecido como uma concentração vertical, onde eram produzidos desde a matéria-prima até o produto acabado; existia também uma intercambiabilidade entre as peças e um maquinário padronizado, não era flexível, esse tipo de produção era caracterizado em produzir em grandes quantidades onde muitas vezes não se importavam muito com a inspeção da qualidade de seus produtos.

\section{- PRODUÇÃO ENXUTA}

Todo esse processo de evolução foi de grande importância para o desenvolvimento no meio produtivo até se chegar a um novo patamar, por volta da década de 50, surge na Ásia, em especial no Japão, um novo conceito de produção: o Sistema de produção enxuta, também conhecida como sistema Just-in-time (JIT) de produção, este sistema surgiu em meio a um período pós-guerra, onde as empresas japonesas buscavam de alguma forma suprir as necessidades industriais e solucionar os problemas ocasionados durante a $2^{\mathrm{a}}$ guerra mundial.

Segundo Martins (1993), o sistema de manufatura enxuta se difere dos demais sistemas em diversos aspectos, desde a administração dentro da organização até os operários e os processos envolvidos no meio produtivo.

\subsection{SISTEMA JUST-IN-TIME}

Segundo Slack et. al. (2007), o JIT significa produzir bens e serviços no momento em que são necessários, visando o não surgimento de estoques e também que seus clientes sejam atendidos de forma rápida, ele afirma que o JIT busca uma maior eficiência e qualidade, ou seja, "O JIT visa atender a demanda instantaneamente, com qualidade perfeita e sem desperdícios”, (SLACK et. al. 2007).

Para que se possa compreender de maneira clara a diferenciação entre a abordagem JIT da abordagem tradicional de manufatura é necessária uma análise do contraste entre os dois sistemas, segundo o autor a abordagem tradicional age como um fato isolador nos estágios de produção, ou seja, após cada estágio os componentes que 
são produzidos são enviados para um estoque que "isola" aquele estágio do próximo estágio de produção.

Segundo Slack et. al. (2007), quanto maior o estoque isolador maio o grau de independência de cada estágio, portanto menores são os danos causados quando ocorre um problema, segundo o autor o principal argumento contra esse tipo de abordagem está sobre o que sua própria condição visa promover, a independência entre os estágios produtivos, ou seja, quando um problema aparece em determinado estágio ele não se torna aparente de forma rápida aos outros estágios, a responsabilidade da resolução deste possível problema está apenas nas pessoas envolvidas naquele estágio de produção, fazendo com que as conseqüências do problema não sejam transmitidas aos demais estágios. Já na abordagem JIT os componentes são produzidos e transmitidos diretamente ao estágio seguinte para serem processados. Os problemas em qualquer estágio têm efeito bem diferente do que os efeitos na abordagem tradicional, ou seja, com a redução de estoques, a fábrica amplia as chances de sua eficiência intrínseca ser aprimorada.

\subsection{PLANEJAMENTO E CONTROLE DA PRODUÇÃO (PCP)}

Para Slack et. al. (2007), o principal propósito do Planejamento e Controle da Produção (PCP) é garantir que os processos da produção sejam utilizados com eficácia e eficiência, e que as organizações produzam produtos e serviços conforme as reais necessidades de seus clientes. Zaccarelli (1996) apud Strunello (1999) conceitua o PCP como sendo um grupo de funções que estão inter-relacionados onde o objetivo é comandar todo o processo, e também coordená-los com os demais setores administrativos de toda organização, ou seja, segundo os autores o PCP nada mais é do que uma ferramenta utilizada pelas organizações para controlar todo o processo, desde seu início até seu término buscando interagir todos os envolvido no processo, de modo a reduzir custos e eliminar os desperdícios em todo meio organizacional, ou seja, segundo Slack et. al. (2007) o PCP é uma ferramenta conectora entre suprimento e demanda, onde os diferentes aspectos dos mesmos e suas diversas circunstâncias devem ser conciliados, portanto o propósito geral do PCP se torna o mesmo, fazer a conexão entre suprimento e demanda que, de certa forma, dispara a produção para que possa satisfazer seus clientes. 


\subsection{DIFERENÇA ENTRE PLANEJAMENTO E CONTROLE}

De acordo com Slack et. al. (2007), não existe uma diferença clara entre planejamento e controle, nem teoricamente e nem na prática, porém existem algumas particularidades em suas características que distinguem os dois fatores:

\subsubsection{PLANEJAMENTO}

- Um plano é uma formalização do que se pretende conseguir em certa etapa futura;

- Não garante que o evento vá acontecer, pois é uma declaração de intenção;

- Os planos baseiam-se em expectativas, e expectativas são esperanças quanto ao futuro.

Quando se planeja algo nem sempre as coisas acontecem conforme o esperado, pois existem fatores constantemente alteráveis e muito flexíveis, fatores esses muitas vezes incontroláveis pela organização. São eles:

- Necessidades reais dos clientes;

- $\quad$ Disponibilidade dos fornecedores;

Saúde dos funcionários.Exemplo: ao planejar sua produção a organização leva em consideração que tudo ocorrerá conforme o esperado, porém qualquer alteração em um dos três fatores citados acima pode ocasionar um atraso no que foi planejado anteriormente pela organização.

\subsubsection{CONTROLE}

Segundo Slack et. al. (2007) controlar é o processo de lidar com possíveis alterações no que foi planejado, significa que os planos precisam ser reelaborados em curto prazo, também pode significar que será necessário uma "intervenção" na operação para que a mesma possa voltar a ocorrer normalmente como esperado, exemplo: encontrar fornecedores disponíveis quando o problema for com a disponibilidade dos mesmos, fazer modificações no processo conforme necessidade dos clientes, mover os funcionários de uma parte a outra para suprir ausências. No geral o controle tem o propósito de corrigir possíveis problemas inesperados no planejamento, a fim de alinhar o meio produtivo para o caminho antes planejado, ou seja, o controle seria um conjunto de ações que direcionam o plano, monitorando o que está acontecendo e alterando o que for necessário para o andamento normal das atividades. 


\subsection{COMPOSIÇÃO DO PLANEJAMENTO E CONTROLE DA PRODUÇÃO}

Moreira (1996) apud Strunello (1999) divide o PCP em três etapas:

- $\quad$ Planejamento da capacidade, onde se refere ao longo prazo;

- $\quad$ Planejamento agregado, referindo ao médio prazo;

- $\quad$ Programa-mestre de produção, curto prazo.

Para Slack et. al. (2007), em longo prazo os gerentes de produção têm planos relativos sobre o que está se pretendendo fazer, os recursos que existem e onde pretendem chegar com esse planejamento, enfatiza-se mais o planejar do que o controlar; já em médio prazo, os gestores preocupam-se em planejar detalhadamente (e re-planejar caso necessite), eles examinam futuramente avaliando a demanda que a operação deve atingir e a curto prazo, muitos dos recursos já terão sido definidos e ficará difícil fazer grandes mudanças, porém há possibilidade de intervenção em curto prazo onde são possíveis caso as coisas não saiam conforme planejado.

Tubino (1999) apud Strunello (1999) classifica de forma semelhante à composição do PCP, entretanto com outra nomenclatura, primeiramente é feito um planejamento estratégico da produção, logo após é realizado o planejamento-mestre da produção e em seguida a programação da produção.

\subsection{MODELO DE REFERÊNCIA PARA GESTÃO DA PRODUÇÃO}

Segundo Bremer; Lenza (2000) estes modelos de referência estão motivados por pesquisas que são desenvolvidas pelo Grupo de Logística Integrada - LI do núcleo de Manutenção Avançada - NUMA, suas atividades visam o planejamento, implementação, controle e otimização do fluxo das empresas onde estão sendo englobadas as áreas do Planejamento e Controle da Produção.

Segundo os autores, todo processo de gestão da produção não ocorre de forma única nas empresas, o mesmo deve ser modelado conforme as restrições de vários tipos de sistemas produtivos. Segundo Pires (1995) apud Bremer; Lenza (2000) existem quatro tipologias de produção básicas, onde é possível estar diferenciando os sistemas produtivos pelo grau de participação do cliente final com o produto, sendo estas tipologias: 
- $\quad$ Produção para Estoque (MTS - Make to Stock) é caracterizada pelos sistemas que produzem com alta padronização, onde é baseado principalmente em previsões de demandas;

- Montagem sob Encomenda (ATO - Assembly to Order) caracterizada por sistemas em que existem subconjuntos onde os materiais são armazenados até o recebimento dos pedidos dos clientes;

- Produção sob Encomenda (MTO - Make-to-Order) pode ser desenvolvida a partir do contato inicial com os clientes, porém a produção só será executada após o fechamento dos pedidos pelos clientes;

- $\quad$ Engenharia sob Encomenda (ETO - Engineering to Order) é quando todo o projeto do produto é feito conforme especificações dos clientes.

Segundo Bremer e Lenza (2000) essas quatro tipologias são que definem ou direcionam as atividades componentes do processo de gestão da produção. A figura 1 demonstra o grau de envolvimento do cliente com o produto conforme avaliação dos autores.

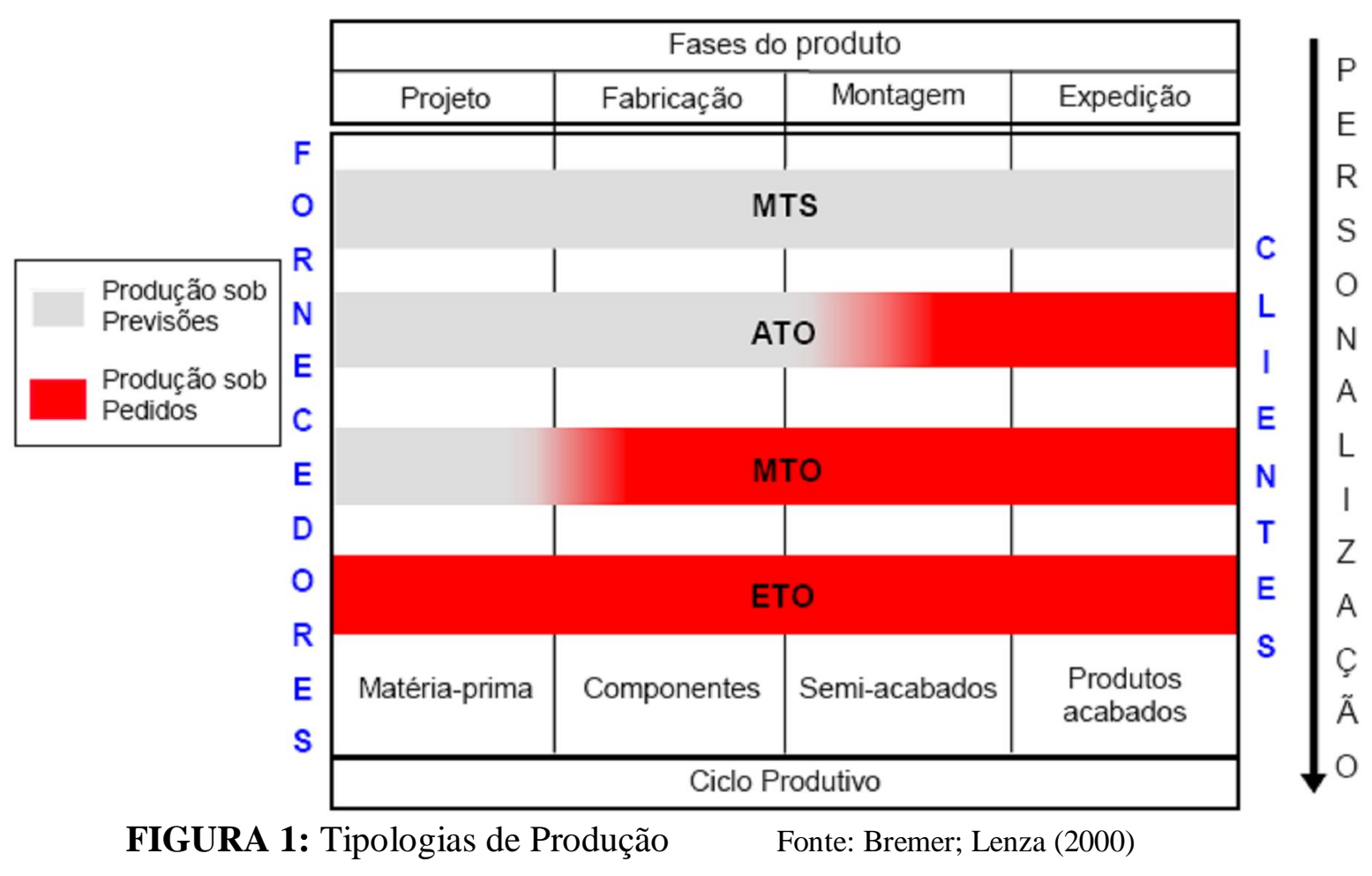

\subsection{DIFERENCIAÇÃO DOS MODELOS DE REFERÊNCIA PARA A GESTÃo DA PRODUÇÃO}


Dentro do planejamento cada modelo se destaca por sua particularidade, como se pode observar no estudo de Bremer; Lenza (2000), além destes fatores citados alguns autores destacam uma série de diferenças nestes modelos.

- $\quad$ MTS - Na produção para estoque, segundo Torres; Fernandes (2005), os custos podem ser mais elevados, pois é encontrado também o custo de manutenção de estoque (custo de estocagem), por outro lado o lead-time

- para entrega é relativamente baixo, pois os produtos finais encontram-se estocados, sua capacidade de produção é limitada à capacidade de armazenagem de seus estoques, os produtos não são variáveis à necessidade dos clientes;

- $\quad$ MTO - Segundo Torres; Fernandes (2005) este modelo diferencia-se do MTS em diversos fatores, não há estoques de produtos finais, com isso não há custos de armazenagens de seus produtos, o prazo para entrega (lead-time) é previamente combinado com o cliente, o produto torna-se configurável as necessidades do cliente;

- ATO - Pacheco; Cândido (2001) concluem que neste modelo o produto tem sua fabricação mediante previsões de demanda, onde seus componentes são armazenados antes da chegada dos pedidos, ou seja, o produto é previamente concluído tendo sua finalização somente após a conclusão do pedido pelo cliente, com isso são armazenados somente componentes com alta demanda, tendo seu lead-time reduzido conforme a ótica dos clientes, onde a empresa torna-se apta para realizar a entrega dos produtos com tempo reduzido;

- ETO - Segundo Pacheco; Cândido (2001) este sistema é semelhante ao MTO, porém neste caso o produto é todo projetado conforme necessidade dos clientes tem sua fabricação altamente customizada.

\section{ESTUDO DE CASO}

\subsection{APRESENTAÇÃO DA EMPRESA}

A empresa analisada está no mercado de metalurgia há nove anos, inicialmente a mesma denominava-se cooperativa de produtos para caldeiraria, porém com o vasto crescimento de seu mercado seus cooperados perceberam a necessidade de crescimento 
da empresa para que pudessem estar se mantendo cada vez mais no mercado siderúrgico, a partir desta necessidade de crescimento a mesma passa a se denominar metalúrgica para poder acompanhar o mercado cada vez mais exigente, hoje a empresa conta com um total de 130 colaboradores no seu meio produtivo, além disso, conta com 28 sócio-cooperados onde os mesmos fazem parte do corpo gerencial da empresa, cada sócio é responsável por uma atividade dentro da empresa, onde estão diretamente ligados a todos os níveis organizacionais. Hoje a empresa conta com um total aproximado de 250 clientes, a mesma tem sua produção focada principalmente para seus maiores clientes, que hoje se encontram no setor sucroalcooleiro, a empresa analisada atualmente se encontra em processo de crescimento devido às novas adesões de clientes e ao vasto crescimento do mercado metalúrgico no país.

\subsection{RESULTADOS ENCONTRADOS}

Para a elaboração deste estudo de caso foi utilizado um roteiro de entrevista onde o foco principal foi o corpo gerencial da empresa, este roteiro foi aplicado na organização para seus gerentes e seu engenheiro responsável pelo processo de produção da empresa, com base neste roteiro chega-se a seguinte conclusão sobre o setor analisado:

Pode-se verificar que os principais problemas encontrados pela empresa para manter seu meio produtivo com a adesão deste sistema esta na relação com seus fornecedores, hoje ela conta com uma série de distribuidoras que fornecem a matériaprima para a empresa, no entanto como está inserida em um mercado relativamente em crescimento pode ocorrer a falta de matéria-prima no mercado nacional, o que obriga a mesma a buscar novas alternativas para conseguir cumprir os prazos estabelecidos no momento da contratação de um serviço, ou seja, a empresa passa a depender de matériaprima vinda do exterior, o que pode ocasionar um aumento no custo de produção da mesma, além destas distribuidoras uma opção seria adquirir a matéria-prima diretamente das siderúrgicas, porém hoje não se torna viável a empresa essa opção devido ao fato da mesma trabalhar com produção sob encomenda, pois as siderúrgicas fornecem matéria-prima através de cotas, onde uma empresa que trabalha sob encomenda não se pode comprometer em adquirir cotas fixas devido ao fato de depender de seus clientes para sua produção, caso a mesma opte por adquirir estas cotas, ocorreria um aumento no custo de armazenagem deste material tornando está hipótese 
inviável para a organização. Segundo seu engenheiro hoje a empresa utiliza em torno de 500 toneladas/mês de chapas de aço para construção de tanques e outros produtos que derivam de seus materiais, como em todo processo de produção há perdas, não se pode deixar de destacar que a empresa obtém mensalmente uma perda de erca de $1 \%$ de matéria-prima o que corresponde a 60 toneladas/ano de material não aproveitado por ela, onde o mesmo é revendido a terceiros que trabalham com reciclagem destes materiais, ou seja, de alguma forma todo material não aproveitado no meio produtivo é reaproveitado. Apesar de ter uma estrutura bem elaborada a empresa ainda necessita de uma terceirização de algumas áreas dentro do seu meio produtivo, por exemplo: todo processo de pintura das peças e principalmente a montagem de alguns produtos nas empresas dos principais clientes, para esse processo é necessário a terceirização para estar concluindo as atividades conforme o prazo contratado pelo cliente.

Hoje a empresa conta com aproximadamente 250 clientes onde o maior potencial destes está inserido no setor sucroalcooleiro, conforme análise das informações percebe-se que hoje as usinas são os clientes que mais contratam as atividades da empresa, entretanto são as que mais exigem pontualidade em relação a prazos estabelecidos inicialmente mediante fechamento do negócio, apesar da empresa ter seu foco voltado para o cumprimento destes prazos não se pode esquecer-se de destacar que pode ocorrer uma série de problemas externos (ameaças) que a empresa não consegue controlar, por exemplo, para se construir um tanque de álcool para uma usina, o processo é feito quase todo em um campo de obras onde será inserido o produto com isso, pode-se destacar que, além do comprometimento da empresa em estar cumprindo os prazos temos a questão do tempo e outros fatores não controláveis pela empresa que pode influenciar no andamento normal da obra, quando ocorre algum problema desta natureza a empresa analisada busca uma nova negociação com seu cliente a fim de evitar uma possível multa devido a atrasos provenientes de fatores não controláveis pela organização. Além destes fatores existe a situação de que todo processo de montagem destes materiais serem feitos por construtoras terceirizadas o que, de certa forma, obriga a empresa a ter uma atenção mais focada no ambiente de trabalho, pois um atraso proveniente da construtora pode ocasionar transtornos para a empresa junto a seus clientes, para evitar estes tipos de transtornos à empresa conta com um membro de seu corpo gerencial e um técnico em segurança em cada canteiro de obras, além disso, cada obra contratada conta com um seguro para evitar transtornos caso ocorra alguma fatalidade em seu meio produtivo. 
Apesar de a empresa estar focada no modelo Make-to-Order pode-se destacar que a mesma também se encaixa no modelo Engineering to Order, pois também há a possibilidade dos clientes estarem envolvidos desde a engenharia do produto até sua produção, neste caso a empresa analisada estaria terceirizando os serviços de engenharia para a elaboração do projeto proposto por seu cliente, atualmente, conforme informações obtidas, a empresa não está utilizando este modelo, seu foco principal está na produção sob encomenda.

Atualmente o mercado encontra-se em expansão e com alto índice de encomendas para a empresa, o que proporciona a mesma manter seu quadro fixo de colaboradores, todavia neste modelo de referência é inviável afirmar que há estabilidade para os funcionários, pois a manutenção dos mesmos depende do andamento da produção, ou seja, neste modelo a rotação de funcionários se torna constante, por exemplo: se a empresa estiver com muitos pedidos o quadro de funcionários tende a aumentar, ocorrem mais contratações, por outro lado se não há pedidos fica difícil a permanência de um número elevado de funcionários, este fato pode ocasionar perda de profissionais qualificados, visto que, em se tratando de um mercado competitivo a procura por profissionais qualificados é grande, e no caso da empresa ter que dispensar funcionários no momento de baixa demanda pode ocasionar que, quando a demanda aumentar estes profissionais não estejam disponíveis no mercado, no momento a empresa trabalha em um regime de turno único, mas caso seja necessário pode estar contratando novos funcionários e trabalhar 24 horas diárias para isso depende do número de pedidos que recebe.

Em se tratar de novos clientes a empresa muitas vezes reduz sua margem de lucro procurando conseguir oferecer um preço menor e ter o pedido, no caso de alguma alteração nos valores da matéria-prima após o fechamento da cotação ou a mesma ainda estiver em andamento à empresa negocia com seus clientes com o objetivo de não influenciar no preço final e conseguir oferecer um produto de qualidade e com melhor preço a seus clientes.

Contanto, estar trabalhando a nove anos no mercado, produzindo materiais muitas vezes similares, vale destacar que não há possibilidade da mesma estar estocando produtos em elaboração, todo projeto da empresa parte do zero, devido ao fato de cada cliente ter sua particularidade e a instalação de seus produtos dependerem de diversos fatores não controláveis pela empresa, tais como: local de instalação; prazo para instalação; particularidade dos clientes. 
No geral este modelo de referência no momento é o mais viável à empresa, pois seu produto trata-se de materiais muito variáveis e a demanda muitas vezes não é constante, a mesma depende da variação dos preços no mercado (matéria-prima) para que possa estar cada vez mais se adequando a constantes mudanças de mercado, mudanças essas que podem influenciar em todo processo de decisão dentro da organização.

\section{CONSIDERAÇÕES FINAIS}

Com análise das informações obtidas chega-se a conclusão de que hoje o melhor modelo de referência dentro da gestão da produção para uma empresa do setor metalúrgico seria o Make-to-Order (MTO) dado que à grande exigência do mercado, onde o setor pode se adequar também ao Engineering to Order (ETO) conforme avaliado em suas respectivas descrições, as empresas especialistas no mercado metalúrgico utilizam deste sistema para conseguir acompanhar o crescimento do setor. Outro fator de destaque é a possível escassez de matéria-prima, o que obriga a empresa a estar buscando novos fornecedores (importação de matéria-prima) o que pode ocasionar um aumento relativo em seus custos de produção.

Conclui-se também que no setor dificilmente há estabilidade para os trabalhadores devido ao fato do meio produtivo ser dependente da demanda. Este modelo adéqua-se exclusivamente as necessidades dos clientes, onde a produção essa dependente destas necessidades pode-se destacar como desvantagem deste modelo o fato da empresa necessitar de terceirizar algum setor dentro do meio produtivo o que pode acontecer, caso tenha algum imprevistos com essas empresas terceirizadas, um atraso na entrega dos produtos aos clientes. Ainda que exista essa desvantagem é possível concluir que este modelo de referência ainda assim se torna o mais eficaz para as empresas do setor metalúrgico, tanto para se adequar às necessidades dos clientes, quanto para conseguir se manter na concorrência exigida pelo mercado.

\section{REFERÊNCIAS}

ANDRADE, J. H. Planejamento e controle da produção na pequena empresa, estudo de caso de fatores intervenientes no desempenho de um empreendimento metalúrgico da cidade de São Carlos - SP. Dissertação de mestrado em engenharia de Produção, Escola de Engenharia de São Carlos, departamento de Engenharia de Produção - USP, São Carlos - SP, 2007. 
BREMER, C. F.; LENZA, R. de P. Um modelo de referência para gestão da produção em sistemas de produção Assembly to Order - ATO e suas múltiplas aplicações. Revista Gestão e Produção, v.7, n.3, p. 269-282; São Carlos, 2000.

CHIAVENATO, I. Teoria geral da administração. 6 ed. São Paulo: Campus, 2000.

CORREA, H. L.; GIANESI, I. G. N. Just-in-Time, MRP II e OPT: um enfoque estratégico; 2 ed. São Paulo: Atlas, 1993.

MAGNOLI, D.; ARAÚJO, R. Geografia: paisagem e território, geografia geral do Brasil. São Paulo: Moderna, 1993.

MARTINS, R. A. Flexibilidade e integração no novo paradigma produtivo mundial: estudo de casos. Dissertação de mestrado em engenharia de Produção, Escola de Engenharia de São Carlos, departamento de Engenharia de Produção - USP, São Carlos - SP, 1993.

MOREIRA, D. A. Administração da produção e operações. In: STRUNELLO, L. D. P. Proposta para planejamento e controle da produção e custos para pequenas empresas do setor de vestuário. 1999. Dissertação (Mestrado em Engenharia de Produção). Programa de pós-graduação em Engenharia de Produção, Universidade Federal de Santa Catarina. Florianópolis.

PACHECO, R. F.; CANDIDO, M. A. B. Metodologia de Avaliação da viabilidade de mudança de estratégia de gestão da demanda de Make-to-Order para Assemblyto-Order. Pontifícia Universidade Católica do Paraná, Programa de pós graduação em Informática aplicada, Paraná: 2001.

PIRES, S. R. I. Gestão estratégica da manufatura. In BREMER, C. F.; LENZA, R. de P. Um modelo de referência para gestão da produção em sistemas de produção Assembly to Order - ATO e suas múltiplas aplicações. Revista Gestão e Produção, v.7, n.3, p. 269-282; São Carlos, 2000.

SLACK, N.; CHAMBERS, S.; JOHNSTON, R. Operations management: administração da produção. 2 ed. 7. reimpr. São Paulo: Atlas, 2007.

TORRES, M. D. M. e FERNANDES, P. Planejamento e Gestão da Produção: Planejamento da Produção, das Capacidades e dos Materiais. Departamento de Engenharia Informática, Faculdade de Ciências e Tecnologia: Universidade de Coimbra; Coimbra - Portugal, 2005.

TUBINO, D. F. Sistemas de produção: a produção no chão de fabrica. In: STRUNELLO, L. D. P. Proposta para planejamento e controle da produção e custos para pequenas empresas do setor de vestuário. 1999.Dissertação (Mestrado em Engenharia de Produção). Programa de pós-graduação em Engenharia de Produção, Universidade Federal de Santa Catarina. Florianópolis.

ZACCARELLI, S. B. Programação e controle da produção.In: STRUNELLO, L. D. P. Proposta para planejamento e controle da produção e custos para pequenas empresas do setor de vestuário. 1999. Dissertação (Mestrado em Engenharia de Produção). Programa de pós-graduação em Engenharia de Produção, Universidade Federalde Santa Catarina Florianópolis. 
ANEXOS:

\section{- Questionário aplicado:}

01) Como a utilização da produção sob encomenda pode influênciar no processo de decisão gerencial da empresa?

02) Quais as principais mudanças que ocorreram na empresa a partir do momento da utilização deste sistema de produção?

03) Houve conflitos dentro da organização com o início da utilização deste sistema?Caso a resposta seja positiva indique quais foram e como foram superados.

04) Na utilização de um sistema onde se produzem sem estoques quais são os problemas encontrados pela empresa para poder se encaixar no mercado? Esses problemas são resolvidos facilmente?

05) Quais as principais vantagens e desvantagens encontradas pela organização com a utilização deste sistema?

06) Economicamente, a utilização do sistema de produção sob encomenda é eficaz perante as metas estabelecidas pela empresa?

07) Perante os principais concorrentes, qual o diferencial encontrado pela empresa para se manter no mercado? Quais seriam os principais concorrentes.

08) Para a gerência em um todo, qual a visão obtida perante aos clientes em relação à utilização deste sistema?

09) Qual a visão gerencial sobre os principais sistemas produtivos existentes no mercado e sobre o sistema utilizado pela organização?

10) No ambiente de trabalho (operacional) como é feita a distribuição das funções com a utilização deste sistema de produção?

11) Como é o retorno dos clientes em relação aos prazos estabelecidos pela empresa para a produção sem estoques (sob encomenda)?

12) Qual a influência do sistema produtivo utilizado pela empresa em se tratando do relacionamento entre os colaboradores do meio produtivo?

13) Qual a visão geral dos responsáveis pelo meio operacional sobre este sistema utilizado pela empresa? 